\title{
Assessment and Determination of Bittering Agents, Essential Oils, and Antioxidants of Gesho (Rhamnus prinoides L. Herit) Collected from Amhara Region, Ethiopia
}

\author{
Abebe Worku Negash $\mathbb{D}^{1},{ }^{1}$ Belay Tilahun Tadesse ${ }^{(D)},{ }^{2}$ and Berhanu Andualem Tsehai ${ }^{2}$ \\ ${ }^{1}$ Department of Biotechnology, College of Natural and Computational Science (CNCS), Adigrat University, P.O. Box 50, \\ Adigrat, Ethiopia \\ ${ }^{2}$ Institute of Biotechnology (IoB), University of Gondar, P.O. Box 196, Gondar, Ethiopia
}

Correspondence should be addressed to Abebe Worku Negash; aworku290@gmail.com

Received 20 August 2020; Revised 28 October 2020; Accepted 18 February 2021; Published 22 February 2021

Academic Editor: Luis F. Guido

Copyright ( 2021 Abebe Worku Negash et al. This is an open access article distributed under the Creative Commons Attribution License, which permits unrestricted use, distribution, and reproduction in any medium, provided the original work is properly cited.

\begin{abstract}
Rhamnus prinoides (Gesho) is an angiosperm dioecious plant, which is used for cash income, as a bittering agent for the preparation of the local alcoholic beverage and medicinal values. Although it has intense use, still its practical application is limited for local alcoholic beverage preparation, and there is no sufficient scientific report on the level and quantity of bittering agents, essential oils, and antioxidants of this plant. Therefore, the objective of this research was to assess and determine the bittering agents, essential oils, and antioxidants of $R$. prinoides. The leaves of $R$. prinoides were collected from eleven different sample sites and allowed to sun dry and then powdered. It was further dried in an oven at $60^{\circ} \mathrm{C}$ for $1 \mathrm{~h}$, and then, total resin, essential oils, alpha acid, iso-alpha acid, beta acid, flavonoids, and polyphenols of $R$. prinoides were determined. All the data were analyzed using SPSS version 20.0. Based on this study finding, $(16.03 \pm 0.03-17.05 \pm 0.04 \%)$ total resins, $(10.00 \pm 0.08-11.23 \pm 0.07 \%)$ soft resins, (5.65 $\pm 0.11-6.40 \pm 0.35 \%)$ hard resins, $(1.82 \pm 0.11-3.14 \pm 0.02 \mathrm{mg} / \mathrm{l})$ alpha acids, $(2.26 \pm 0.15-4.15 \pm 0.10 \mathrm{mg} / \mathrm{l})$ iso-alpha acids, $(2.62 \pm 0.04-4.29 \pm 0.08 \mathrm{mg} / \mathrm{l})$ beta acids, $(7.74 \pm 0.11-12.47 \pm 0.13 \%)$ essential oils, $(23.00 \pm 0.14-25.01 \pm 0.09 \%)$ flavonoids, and $(2.11 \pm 0.01-2.41 \pm 0.02 \%)$ polyphenols were obtained in the leaves of $R$. prinoides. $R$. prinoides leaves taken from Tikledingay has shown statistically $(P \leq 0.05)$ significant amount of soft resin $(11.23 \pm 0.07 \%)$, alpha acid $(3.14 \pm 0.02 \mathrm{mg} / \mathrm{l})$, iso-alpha acid $(4.15 \pm 0.10 \mathrm{mg} / \mathrm{l})$, essential oils $(12.47 \pm 0.13 \%)$, flavonoids $(25.01 \pm 0.09 \%)$, and polyphenols $(2.41 \pm 0.02 \%)$ in comparison with other samples. Generally, R. prinoides is a good source of bittering agents, essential oils, and antioxidants. However, the quantity of bittering agents, essential oils, and antioxidants in the leaves of $R$. prinoides was varied with sample collection sites. So $R$. prinoides can be used as a substitute for commercial hops used in the breweries, and promotion should be done to introduce the potential of Gesho as a bittering agent, source of aroma and flavor, and also antioxidant for beer and other alcoholic beverages.
\end{abstract}

\section{Introduction}

Rhamnus prinoides, Gesho in Amharic, is a dicotyledonous angiosperm, which belongs to the genus Rhamnus under the family Rhamnaceae. It is commonly known as dark blinkblaar, dogwood, and shiny leaf [1]. R. prinoides is a dense shrub or small tree which grows up to 6 meters tall. It is one of the two species that represent the genus Rhamnus and a widespread plant species in Africa [2]. The plant is native to Ethiopia, Eritrea, Botswana, Namibia, Lesotho,
Swaziland, South Africa, and Uganda and also exotic to Kenya. It also occurs in Cameroon, Sudan, Angola, and Arabia [3].

R. prinoides finds therapeutic applications in traditional medicine. Aqueous tinctures containing Gesho have been used to treat arthritis, back pain, brucellosis, flu, common cold, indigestion, loss of appetite, pneumonia, fatigue, sexually transmitted diseases, stomach aches, and ear pain, nose, and throat infections $[4,5]$. In particular, a mixture of crushed Gesho leaves and butter was used as an ointment for 
the treatment of atopic dermatitis [6]. The fruits of this plant are used for ringworm infection treatment [3].

The different chemical compounds, such as musizin, sorigenin, geshoidin, chrysophanol, physcion, emodin, 10oxoprinoidin, quercetin, 3-O-methylquercetin, rhamnocitrin, and rhamnazin, were isolated from the leaves of $R$. prinoides. Of the various chemical substances found in $R$. prinoides, naphthalene glucoside named geshoidin is responsible for the bitter attributes of the plant [3]. Geshoidin is a nontoxic substance found in abundant quantities in the stem and leaves of $R$. prinoides [7]. R. prinoides is quite different from hops (Humulus lupulus) and is grown largely in Ethiopia and is currently available in the local market in the dried form [8]. For hundreds of years, it has been used as a bittering agent in the traditional brewing process in East Africa [9].

In Ethiopia, $R$. prinoides is mainly used to provide bitterness, a special aroma, and flavor for traditional alcoholic drinks $[10,11]$. The leaves and stems of the plant are used to impart the characteristic bitter taste to domestically produced beverages, such as Tella and Tej, and it has been estimated that more than 5 million people consume it every day [12]. Gesho leaves and stems are essential ingredients in the preparation of these traditional fermented beverages. The plant has been reported to regulate the microflora responsible for the fermentation process. It plays an important role in suppressing certain bacteria during the fermentation process [13].

Hop is the basic ingredient used for bittering, flavoring, and aroma imparting agent for beer production. Also, it has a bacteriostatic activity to inhibit the growth of most microorganisms [14]. $R$. prinoides can serve as a substitute for hops used in beer production [8].

Although $R$. prinoides has intense use, its practical application has been limited for traditional/local alcoholic beverages preparation [15]. Also, no sufficient previous scientific report was found on the level and quantity of bittering agents, essential oils, and antioxidants in the leaves of this plant cultivated in different parts of Ethiopia and elsewhere. Hence, to use the leaves of this plant as a bittering agent, sources of aroma and flavor, and also as an antioxidant in beer brewing and other commercial alcoholic beverages preparation, the assessment and determination of its different physicochemical characteristics are significant. Therefore, the objective of this research is to assess and determine the bittering agents, essential oils, and antioxidants of Rhamnus prinoides (Gesho), collected from different cultivation places of the Amhara region, Ethiopia.

\section{Materials and Methods}

2.1. Description of the Study Area and Study Design. The study area was included central Gondar Zone (Delgie, Gondar, Kola Diba, and Tikledingay), North Gondar Zone (Debark), West Gojjam Zone (Finote Selam), South Gondar Zone (Ambessamie, Debre Tabor, and Wereta), North Wollo Zone (Geregera), and Awi Zone (Injibara). The collected leaf samples were investigated in the Microbial and Organic Chemistry laboratory, University of Gondar, Ethiopia. It is located at a distance of $727 \mathrm{~km}$ away from Addis Ababa, the capital city of Ethiopia. In this study, an experimental research design was employed.

2.2. Sample Collection and Transportation. A sampling of $R$. prinoides leaves was done using purposive sampling techniques. Fresh leaves of $R$. prinoides were collected and then sun-dried in the sample collection areas. The leaf samples collected were labeled and placed in polyethylene plastic bags. Then, it was brought to the University of Gondar, Microbial, and Organic Chemistry laboratory for further pretreatment and analysis.

2.3. Sample Preparation. The collected sun-dried $R$. prinoides leaves samples were cleaned manually to remove seeds, stalks, stones, and other extraneous materials. The sun-dried and cleaned leaves samples were crushed and pounded into small pieces of particle size of $0.75 \mathrm{~mm}$ and below with laboratory Miller. It was then further dried in an oven at $60^{\circ} \mathrm{C}$ for $1 \mathrm{~h}$ to remove the moisture content of leaves powder. The powdered leaf samples were stored in plastic bags in a cool and dry place, and then, laboratory analysis of the leaves sample was carried out to determine the bittering agents, essential oils, and antioxidants of $R$. prinoides.

\subsection{Determination of Bittering Agents of R. prinoides}

2.4.1. Total Resin Determination. Twenty (20) grams of the leaves sample of $R$. prinoides was dissolved in $100 \mathrm{ml}$ of cold methanol (99.5\%, Sisco Research Laboratories Pvt. Ltd, India) in a conical bottom flask, and the mixture was vigorously agitated by swirling the flask. Thereafter, the solution was filtered using Whatman filter paper (No. 14). The filtrate containing the resin was then dried to constant weight over a water bath. The total resin was then calculated as a percentage of the original weight of the sample dissolved in methanol [16].

2.4.2. Soft Resin and Hard Resin Determination. Twenty (20) grams of the $R$. prinoides leaves sample was dissolved in $20 \mathrm{ml}$ of $n$-hexane (99.9\%, Pentokey Organy Ltd, India) thoroughly stirred and filtered using Whatman filter paper (No. 14). The filtrate was dried to constant weight over a water bath. The soft resin was then calculated as a percentage of the original weight of the sample dissolved in $n$-hexane. A hard resin was determined by subtracting soft resin from total resin [17].

2.4.3. Iso- $\alpha$-Acid Determination. A $0.15 \%(w / v)$ solution of the leaves sample of $R$. prinoides was made using distilled water. The solution was boiled for $90 \mathrm{~min}$ and cooled and filtered using Whatman filter paper (No. 14). A $15 \mathrm{ml}$ sample extract was acidified with $0.5 \mathrm{ml} 6 \mathrm{~N} \mathrm{HCl}$ (35-38\%, Blulux laboratories Pvt. Ltd, India) and mixed with $15 \mathrm{ml}$ of pure isooctane (99.5\% Loba Chemie Pvt. Ltd, India) in a flask shaker, and $10 \mathrm{ml}$ of the isooctane extract was washed with $10 \mathrm{ml}$ of a mixture of methanol and $4 \mathrm{~N} \mathrm{HCl}(68: 32, v / v)$. 
After this, $5 \mathrm{ml}$ of the washed isooctane layer was diluted with $5 \mathrm{ml}$ of alkaline methanol $(60: 40, v / v$ methanol: $0.5 \mathrm{~N}$ $\mathrm{NaOH}$ ), and its absorbance was read at $255 \mathrm{~nm}$ using UVVis spectrophotometer (Abron instruments, India). The iso$\alpha$-acid (mg/l) was calculated according to the [18] method of analysis (iso- $\alpha$-acid $(\mathrm{mg} / \mathrm{l})=\mathrm{A} 255(96.15)+0.4)$.

2.4.4. Alpha- and Beta-Acid Determination. 0.15 grams of the sample was added in $100 \mathrm{ml}$ cold methanol in a flask shaker. The solution was then centrifuged at $2500 \mathrm{rpm}$ for $20 \mathrm{~min}$, and then, decanted supernatant was acidified with $0.002 \mathrm{~N} \mathrm{HCl}$; its absorbance at 355, 325, and $275 \mathrm{~nm}$ was determined using a spectrophotometer and the $\alpha$-acid calculated using [18] method: $\alpha$-acid $(\mathrm{mg} / \mathrm{l})=73.79(\mathrm{~A} 325)-$ $51.56(\mathrm{~A} 355)-19.07$ (A275) and B-acid $(\mathrm{mg} / \mathrm{l})=55.57$ $(\mathrm{A} 355)-47.59(\mathrm{~A} 325)+5.10(\mathrm{~A} 275)$, where $\mathrm{A}$ is the absorbance reading at the specified wavelength.

2.5. Determination of Essential Oils of R. prinoides. Twenty (20) grams of the leaf sample of $R$. prinoides was placed inside a thimble and inserted into the inner tube of the Soxhlet extractor (BS2071, England). This apparatus was then fitted to a round-bottom flask, which contained $200 \mathrm{ml}$ of $n$-hexane. A reflux condenser was also mounted and fitted on the apparatus. The set-up was held tight to a retort-stand and then placed on a suitable electric heating mantle (Type ER, E.E.C) that was switched on for an extraction time of $120 \mathrm{~min}$ at the boiling point of the solvent ( $n$-hexane, $60^{\circ} \mathrm{C}$ ). The vapor was passed up through the tube and condensed by the condenser, and the condensed solvent falls into the thimble and slowly fills the body of the Soxhlet. When the solvent reached the top of the tube, it siphoned over into the flask and thus removed the portion of the sample that has been extracted in the thimble. The solvent recovery process has been done using a rotary evaporator (RE20729, Bibby Sterilin Ltd, England). The mixture of solvent ( $n$-hexane) and oil was heated in the flask over a heater. On constant heating, the solvent evaporated and thereafter condensed in the flask. The condensed solvent was collected into the flask. Then, the extracted oil was recovered, and its mass was recorded and calculated as a percentage from the original sample [16].

\subsection{Determination of Antioxidants of $R$. prinoides}

2.6.1. Determination of Flavonoids. Ten (10) grams of the leaves sample of $R$. prinoides was extracted repeatedly with $100 \mathrm{ml}$ of $80 \%$ aqueous methanol at room temperature. The whole solution was filtered through Whatman filter paper (No. 14). The filtrate was later transferred into a crucible and evaporated to dryness over a water bath and weighed to a constant weight using a sensitive electronic balance [19].

2.6.2. Determination of Polyphenols. The sample was boiled with $50 \mathrm{ml}$ of ether (99\%, Blulux laboratories Pvt. Ltd, India) for the extraction of phenolic component for $15 \mathrm{~min}, 5 \mathrm{ml}$ of the extract was pipetted into a $50 \mathrm{ml}$ flask, and then $10 \mathrm{ml}$ of distilled water was added. A $2 \mathrm{ml}$ of ammonium hydroxide solution (Blulux laboratories Pvt. Ltd, India) and $5 \mathrm{ml}$ of concentrated amyl alcohol (Blulux laboratories Pvt. Ltd, India) was also added. The sample was made up to the mark and left for 30 minutes for color development. This was measured at $505 \mathrm{~nm}$ [20].

2.7. Statistical Analysis. All the data were analyzed using the Statistical Package for Social Sciences (SPSS) version 20.0 program. Mean and standard deviation of the triplicate data were calculated using a one-way analysis of variance (ANOVA). Post hoc multiple comparisons, particularly the Duncan test, was employed to compare the significance between groups. The statistically significant differences were considered at $P \leq 0.05$.

\section{Result and Discussion}

3.1. Determination of Bittering Agents of $R$. prinoides. The quantitative values of total resins, soft resins, hard resins, $\alpha$-acid, iso- $\alpha$-acid, and $\beta$-acid of $R$. prinoides leaves collected from various sample sites are given in Table 1 . Resin is the most characteristic and valuable constituents of the hop. They give beer its bitter taste, improve foam stability, and increase the biological stability of the beer [21]. In this investigation, the amount of total resin content of $R$. prinoides leaves collected from Debark, Debre Tabor, Finote Selam, Injibara, Gondar, Kola Diba, Wereta, Geregera, Delgie, Ambessamie, and Tikledingay were $16.03 \pm 0.03 \%$, $16.05 \pm 0.02 \%, 16.07 \pm 0.15 \%, 16.10 \pm 0.05 \%, 16.24 \pm 0.06 \%$, $16.31 \pm 0.06 \%, \quad 16.60 \pm 0.03,16.66 \pm 0.21 \%, \quad 16.92 \pm 0.04 \%$, $16.98 \pm 0.07 \%$, and $17.05 \pm 0.04 \%$, respectively (Table 1 ). Thus, the amount of total resin content obtained from $R$. prinoides leaves collected from these sample sites were ranged from $16.03 \pm 0.03$ to $17.05 \pm 0.04 \%$ ) and found to be comparable with the total resin values of $R$. prinoides leaves $(18.46 \pm 0.03 \%)$ reported in [8]. And also, the authors in [21] reported that the amount of hop resin ranged from 12 to $24 \%$ with a mean value of $18.5 \%$. In this case, the total resin content of the leaves of $R$. prinoides (16.03 $\pm 0.03-17.05$ $\pm 0.04 \%$ ) was found to be within the range of total resin values of air-dried commercial hop cones. The values of total resin $(16.03 \pm 0.03-17.05 \pm 0.04 \%)$ obtained in this study from $R$. prinoides leaves collected from different sample sites were found less than the total resin values (20.4\%) of Vernonia amygdalina reported in [16].

The total resins represent the sum of all bitter resins and can be further divided into hard and soft resins [22]. Hard resins are insoluble in hexane, and soft resins are soluble in hexane [23]. In this study, the amount of soft resins content obtained from leaves of $R$. prinoides collected from Debark, Gondar, Debre Tabor, Finote Selam, Wereta, Injibara, Kola Diba, Geregera, Delgie, Ambessamie, and Tikledingay were $10.00 \pm 0.08 \%, 10.23 \pm 0.27 \%, 10.30 \pm 0.22 \%, 10.35 \pm 0.15 \%$, $10.36 \pm 0.18 \%, 10.45 \pm 0.08 \%, 10.46 \pm 0.13 \%, 10.50 \pm 0.16 \%$, $10.52 \pm 0.33 \%, 10.86 \pm 0.10 \%$, and $11.23 \pm 0.07 \%$, respectively (Table 1). These values of soft resin ranged from $10.00 \pm 0.08$ to $11.23 \pm 0.07 \%$ depending on sample collection sites and 
TABLE 1: Average concentrations of the bittering components in $R$. prinoides leaves samples collected from different sample sites.

\begin{tabular}{|c|c|c|c|c|c|c|}
\hline \multirow{2}{*}{ Sample sites } & \multicolumn{6}{|c|}{ Values } \\
\hline & Total resin (\%) & Soft resin (\%) & Hard resin (\%) & $\alpha$-Acid (mg/l) & Iso- $\alpha$-acid (mg/l) & $\beta$-Acid $(\mathrm{mg} / \mathrm{l})$ \\
\hline Ambessamie & $16.98 \pm 0.07^{\mathrm{e}}$ & $10.86 \pm 0.10^{\mathrm{c}}$ & $6.12 \pm 0.16^{\mathrm{cde}}$ & $3.08 \pm 0.01^{\mathrm{d}}$ & $3.83 \pm 0.15^{\mathrm{d}}$ & $4.21 \pm 0.03^{f g}$ \\
\hline Debark & $16.03 \pm 0.03^{\mathrm{a}}$ & $10.00 \pm 0.08^{\mathrm{a}}$ & $6.03 \pm 0.07^{\mathrm{bcd}}$ & $1.82 \pm 0.11^{\mathrm{a}}$ & $2.63 \pm 0.10^{\mathrm{b}}$ & $4.06 \pm 0.05^{\mathrm{ef}}$ \\
\hline Debre Tabor & $16.05 \pm 0.02^{\mathrm{a}}$ & $10.30 \pm 0.22^{\mathrm{ab}}$ & $5.74 \pm 0.20^{\mathrm{bc}}$ & $2.66 \pm 0.05^{\mathrm{c}}$ & $2.64 \pm 0.19^{\mathrm{b}}$ & $4.02 \pm 0.19^{\mathrm{e}}$ \\
\hline Delgie & $16.92 \pm 0.04^{\mathrm{e}}$ & $10.52 \pm 0.33^{\mathrm{b}}$ & $6.40 \pm 0.35^{\mathrm{e}}$ & $2.77 \pm 0.02^{\mathrm{c}}$ & $3.18 \pm 0.09^{c}$ & $2.86 \pm 0.10^{\mathrm{b}}$ \\
\hline Finote Selam & $16.07 \pm 0.15^{\mathrm{a}}$ & $10.35 \pm 0.15^{\mathrm{b}}$ & $5.72 \pm 0.03^{b c}$ & $2.35 \pm 0.01^{\mathrm{b}}$ & $2.70 \pm 0.01^{\mathrm{b}}$ & $3.80 \pm 0.07^{\mathrm{d}}$ \\
\hline Geregera & $16.66 \pm 0.21^{\mathrm{d}}$ & $10.50 \pm 0.16^{\mathrm{b}}$ & $6.15 \pm 0.30^{\mathrm{cde}}$ & $2.67 \pm 0.01^{c}$ & $3.02 \pm 0.06^{\mathrm{c}}$ & $3.68 \pm 0.16^{\mathrm{cd}}$ \\
\hline Gondar & $16.24 \pm 0.06^{\mathrm{bc}}$ & $10.23 \pm 0.27^{\mathrm{ab}}$ & $6.01 \pm 0.25^{\mathrm{abcd}}$ & $1.84 \pm 0.12^{\mathrm{a}}$ & $2.26 \pm 0.15^{\mathrm{a}}$ & $3.57 \pm 0.02^{\mathrm{c}}$ \\
\hline Injibara & $16.10 \pm 0.05^{\mathrm{ab}}$ & $10.45 \pm 0.08^{\mathrm{b}}$ & $5.65 \pm 0.11^{\mathrm{a}}$ & $2.36 \pm 0.03^{\mathrm{b}}$ & $2.80 \pm 0.10^{\mathrm{b}}$ & $3.65 \pm 0.14^{\mathrm{cd}}$ \\
\hline Kola Diba & $16.31 \pm 0.06^{\mathrm{c}}$ & $10.46 \pm 0.13^{\mathrm{b}}$ & $5.84 \pm 0.07^{\mathrm{abc}}$ & $2.76 \pm 0.10^{c}$ & $3.67 \pm 0.10^{\mathrm{d}}$ & $3.65 \pm 0.06^{\mathrm{cd}}$ \\
\hline Tikledingay & $17.05 \pm 0.04^{\mathrm{e}}$ & $11.23 \pm 0.07^{\mathrm{d}}$ & $5.81 \pm 0.10^{\mathrm{abc}}$ & $3.14 \pm 0.02^{\mathrm{d}}$ & $4.15 \pm 0.10^{\mathrm{e}}$ & $2.62 \pm 0.04^{\mathrm{a}}$ \\
\hline Wereta & $16.60 \pm 0.03^{\mathrm{d}}$ & $10.36 \pm 0.18^{\mathrm{b}}$ & $6.24 \pm 0.17^{\mathrm{de}}$ & $2.64 \pm 0.09^{c}$ & $2.64 \pm 0.15^{\mathrm{b}}$ & $4.29 \pm 0.08^{g}$ \\
\hline
\end{tabular}

Values are the means of triplicate determinations \pm standard deviation; values within the same column followed by different superscripts are significantly different at $P \leq 0.05$.

were found to be lower than the soft resin values $(15.73 \pm 0.03 \%)$ of $R$. prinoides leaves reported in [8]. But, in this case, the result obtained for soft resin from $R$. prinoides leaves was found to be within the range of soft resin values of $(10-18 \%)$ commercial hops, used for beer production reported in [21].

In contrast, the hard resin content of $R$. prinoides leaves collected from Debark, Gondar, Debre Tabor, Finote Selam, Wereta, Injibara, Kola Diba, Geregera, Delgie, Ambessamie, and Tikledingay was $6.03 \pm 0.07 \%, 6.01 \pm 0.25 \%, 5.74 \pm$ $0.20 \%, 5.72 \pm 0.03 \%, 6.24 \pm 0.17,5.65 \pm 0.11 \%, 5.84 \pm 0.07 \%$, $6.15 \pm 0.30 \%, 6.40 \pm 0.35 \%, 6.12 \pm 0.16 \%$, and $5.81 \pm 0.10 \%$, respectively (Table 1 ). The quantity of hard resins of $R$. prinoides leaves obtained in this investigation from these sample sites ranged from $5.65 \pm 0.11$ to $6.40 \pm 0.35 \%)$ and was higher than the values of the hard resin content $(2.73 \pm 0.01 \%)$ of $R$. prinoides leaves recorded and reported in [8]. As reported in [21], the hard resin content of commercial hop ranged from 2 to $4 \%$. The values of hard resin content obtained in this investigation from $R$. prinoides leaves were found higher than hard resin values of air-dried commercial hop cones reported in [21].

In this study, the amount and quantity of $\alpha$-and $\beta$-acids were also determined. The mean values of $\alpha$-acid obtained from the leaves of $R$. prinoides collected from Debark, Gondar, Finote Selam, Injibara, Wereta, Debre Tabor, Geregera, Kola Diba, Delgie, Ambessamie, and Tikledingay were $\quad 1.82 \pm 0.11 \mathrm{mg} / \mathrm{l}, \quad 1.84 \pm 0.12 \mathrm{mg} / \mathrm{l}, \quad 2.35 \pm 0.01 \mathrm{mg} / \mathrm{l}$, $2.36 \pm 0.03 \mathrm{mg} / \mathrm{l}, \quad 2.64 \pm 0.09 \mathrm{mg} / \mathrm{l}, \quad 2.66 \pm 0.05 \mathrm{mg} / \mathrm{l}, \quad 2.67 \pm$ $0.01 \mathrm{mg} / \mathrm{l}, 2.76 \pm 0.10 \mathrm{mg} / \mathrm{l}, 2.77 \pm 0.02 \mathrm{mg} / \mathrm{l}, 3.08 \pm 0.01 \mathrm{mg} / \mathrm{l}$, and $3.14 \pm 0.02 \mathrm{mg} / \mathrm{l}$, respectively. These values were ranged from $1.82 \pm 0.11$ to $3.14 \pm 0.02 \mathrm{mg} / \mathrm{l}$ and found to be within the range of $\alpha$-acid values of commercial hops reported in [24]. According to [16], the amount of $\alpha$-acid of $V$. amygdalina was $9.27 \mathrm{mg} / \mathrm{l}$. Thus, the quantity of $\alpha$-acid of $R$. prinoides leaves obtained in this study was lower than the $\alpha$-acid values of $V$. amygdalina.

However, the mean values of iso- $\alpha$-acid of $R$. prinoides leaves collected from Gondar, Debark, Wereta, Debre Tabor, Finote Selam, Injibara, Geregera, Delgie, Kola Diba, Ambessamie, and Tikledingay were $2.26 \pm 0.15 \mathrm{mg} / \mathrm{l}$,
$2.63 \pm 0.10 \mathrm{mg} / \mathrm{l}, \quad 2.64 \pm 0.15 \mathrm{mg} / \mathrm{l}, \quad 2.64 \pm 0.19 \mathrm{mg} / \mathrm{l}, \quad 2.70 \pm$ $0.01 \mathrm{mg} / \mathrm{l}, 2.80 \pm 0.10 \mathrm{mg} / \mathrm{l}, 3.02 \pm 0.06 \mathrm{mg} / \mathrm{l}, 3.18 \pm 0.09 \mathrm{mg} / \mathrm{l}$, $3.67 \pm 0.10 \mathrm{mg} / \mathrm{l}, 3.83 \pm 0.15 \mathrm{mg} / \mathrm{l}$, and $4.15 \pm 0.10 \mathrm{mg} / \mathrm{l}$, respectively (Table 1). These values ranged from $2.26 \pm 0.15$ to $4.15 \pm 0.10 \mathrm{mg} / \mathrm{l}$ and were higher than the iso- $\alpha$-acid values $(1.07 \pm 0.02 \mathrm{mg} / \mathrm{l})$ of $R$. prinoides leaves recorded in [25]. The quantity of iso- $\alpha$-acid values obtained in this case in the leaves of $R$. prinoides was low in comparison with the iso$\alpha$-acid values $(8.52 \mathrm{mg} / \mathrm{l})$ of $V$. amygdalina found in the literature [16].

On the contrary, the values of $\beta$-acids of $R$. prinoides leaves taken from Tikledingay, Delgie, Gondar, Kola Diba, Injibara, Geregera, Finote Selam, Debre Tabor, Debark, Ambessamie, and Wereta were $2.62 \pm 0.04 \mathrm{mg} / \mathrm{l}, 2.86 \pm$ $0.10 \mathrm{mg} / \mathrm{l}, 3.57 \pm 0.02 \mathrm{mg} / \mathrm{l}, 3.65 \pm 0.06 \mathrm{mg} / \mathrm{l}, 3.65 \pm 0.14 \mathrm{mg} / \mathrm{l}$, $3.68 \pm 0.16 \mathrm{mg} / \mathrm{l}, \quad 3.80 \pm 0.07 \mathrm{mg} / \mathrm{l}, \quad 4.02 \pm 0.19 \mathrm{mg} / \mathrm{l}, \quad 4.06 \pm$ $0.05 \mathrm{mg} / \mathrm{l}, 4.21 \pm 0.03 \mathrm{mg} / \mathrm{l}$, and $4.29 \pm 0.08 \mathrm{mg} / \mathrm{l}$, respectively (Table 1). So the values of $\beta$-acid of leaves of $R$. prinoides from these sample sites ranged from $2.62 \pm 0.04$ to $4.29 \pm 0.08 \mathrm{mg} / \mathrm{l}$ and were found to be within the range of $\beta$-acid values of commercial hops reported in [24].

3.2. Determination of Essential Oils of $R$. prinoides. The quantity of essential oils found in the leaves of $R$. prinoides collected from different cultivation sites is shown in Table 2. Essential oils are the key contributor to aroma and flavor during beer production [24]. In this case, the amount of essential oils content of $R$. prinoides leaves that was taken from Debark, Wereta, Debre Tabor, Gondar, Kola Diba, Finote Selam, Geregera, Injibara, Ambessamie, Delgie, and Tikledingay was $7.74 \pm 0.11 \%, 7.92 \pm 0.10 \%, 7.99 \pm 0.08 \%$, $8.51 \pm 0.15 \%, \quad 8.75 \pm 0.15 \%, \quad 10.15 \pm 0.30 \%, \quad 10.36 \pm 0.29 \%$, $10.70 \pm 0.15 \%, 11.30 \pm 0.04 \%, 11.47 \pm 0.05 \%$, and $12.47 \pm$ $0.13 \%$, respectively.

So the content of the essential oil obtained in $R$. prinoides leaves was in the range of 7.74 $\pm 0.11-12.47 \pm 0.13 \%$ depending on the sample sites and higher than the content of the essential oil of dried commercial hop cones reported by several authors [21, 24, 26]. Berhanu [8] reported that the mean values of essential oils content of $R$. prinoides leaves 
TABLE 2: Average concentration of essential oils of $R$. prinoides leaves samples collected from different sample sites.

\begin{tabular}{lc}
\hline Sample sites & Essential oils $(\%)$ \\
\hline Ambessamie & $11.30 \pm 0.04^{\mathrm{e}}$ \\
Debark & $7.74 \pm 0.11^{\mathrm{a}}$ \\
Debre Tabor & $7.99 \pm 0.08^{\mathrm{a}}$ \\
Delgie & $11.47 \pm 0.05^{\mathrm{e}}$ \\
Finote Selam & $10.15 \pm 0.30^{\mathrm{c}}$ \\
Geregera & $10.36 \pm 0.29^{\mathrm{c}}$ \\
Gondar & $8.51 \pm 0.15^{\mathrm{b}}$ \\
Injibara & $10.70 \pm 0.15^{\mathrm{d}}$ \\
Kola Diba & $8.75 \pm 0.15^{\mathrm{b}}$ \\
Tikledingay & $12.47 \pm 0.13^{\mathrm{f}}$ \\
Wereta & $7.92 \pm 0.10^{\mathrm{a}}$ \\
\hline
\end{tabular}

*Values are the means of triplicate determinations \pm standard deviation; values within the same column followed by different superscripts are significantly different at $P \leq 0.05$.

were $1.13 \pm 0.02 \%$. So, the content of essential oils obtained in this case $(7.74 \pm 0.11-12.47 \pm 0.13 \%)$ was greater than that of $R$. prinoides leaves reported in [8]. Here, one possible reason for such a difference may be due to the method used. The method used in this study for essential oil extraction and determination was completely different from the methods used in [8]. In this study, the quantity of essential oil from leaves $(7.74 \pm 0.11-12.47 \pm 0.13 \%)$ powder of $R$. prinoides was higher than the content of the essential oil (1.20\%) of $V$. amygdalina reported in [16]. A significant amount of essential oils was obtained in this study, and this indicates that the leaves of $R$. prinoides can be serving as a good source of aroma and flavor in the production of alcoholic beverages.

3.3. Determination of Antioxidants of $R$. prinoides. The concentration of antioxidants in the leaves of $R$. prinoides collected from various sample sites is presented quantitatively in Table 3. In this study, the quantity of flavonoids content obtained from $R$. prinoides leaves sample taken from Debark, Debre Tabor, Wereta, Kola Diba, Gondar, Geregera, Injibara, Finote Selam, Delgie, Ambessamie, and Tikledingay was $\quad 23.00 \pm 0.14 \%, \quad 23.01 \pm 0.10 \%, \quad 23.30 \pm 0.13 \%$, $23.30 \pm 0.17 \%, 23.58 \pm 0.06 \%, 23.71 \pm 0.20 \%, 23.80 \pm 0.05 \%$, $23.82 \pm 0.12 \%, 24.12 \pm 0.33 \%, 25.00 \pm 0.17 \%$, and $25.01 \pm$ $0.09 \%$, respectively (Table 3 ). These values ranged from $23.00 \pm 0.14$ to $25.01 \pm 0.09 \%$ depended on the location of sample sites and found to be comparable with the values of flavonoids of $R$. prinoides leaves $(24.42 \pm 0.13 \%)$ reported in [25].

As it is shown in Table 3, the mean values of polyphenols obtained in this study from $R$. prinoides leaves collected from Debark, Finote Selam, Kola Diba, Delgie, Gondar, Debre Tabor, Geregera, Injibara, Wereta, Ambessamie, and Tikledingay were $2.11 \pm 0.01 \%, 2.12 \pm 0.015 \%, 2.15 \pm 0.023 \%$, $2.17 \pm 0.061 \%, \quad 2.18 \pm 0.01 \%, \quad 2.18 \pm 0.06 \%, \quad 2.27 \pm 0.01 \%$, $2.27 \pm 0.07 \%, 2.32 \pm 0.07 \%, 2.33 \pm 0.06 \%$, and $2.41 \pm 0.02 \%$, respectively. These values of polyphenols ranged from $2.11 \pm 0.01$ to $2.41 \pm 0.02 \%$, depending on the sample collection sites, and were found within the range of the polyphenol values of commercial hop $(2-5 \%)$, which was
TABle 3: Average concentration of antioxidants of $R$. prinoides leaves samples collected from different sample sites.

\begin{tabular}{lcc}
\hline \multirow{2}{*}{ Sample sites } & \multicolumn{2}{c}{ Values } \\
& Flavonoids (\%) & Polyphenols (\%) \\
\hline Ambessamie & $25.00 \pm 0.17^{\mathrm{e}}$ & $2.33 \pm 0.06^{\mathrm{a}}$ \\
Debark & $23.00 \pm 0.14^{\mathrm{a}}$ & $2.11 \pm 0.01^{\mathrm{a}}$ \\
Debre Tabor & $23.01 \pm 0.10^{\mathrm{a}}$ & $2.18 \pm 0.06^{\mathrm{a}}$ \\
Delgie & $24.12 \pm 0.33^{\mathrm{d}}$ & $2.17 \pm 0.061^{\mathrm{a}}$ \\
Finote Selam & $23.82 \pm 0.12^{\mathrm{c}}$ & $2.12 \pm 0.015^{\mathrm{a}}$ \\
Geregera & $23.71 \pm 0.20^{\mathrm{c}}$ & $2.27 \pm 0.01^{\mathrm{b}}$ \\
Gondar & $23.58 \pm 0.06^{\mathrm{bc}}$ & $2.18 \pm 0.01^{\mathrm{a}}$ \\
Injibara & $23.80 \pm 0.05^{\mathrm{c}}$ & $2.27 \pm 0.07^{\mathrm{b}}$ \\
Kola Diba & $23.30 \pm 0.17^{\mathrm{b}}$ & $2.15 \pm 0.023^{\mathrm{a}}$ \\
Tikledingay & $25.01 \pm 0.09^{\mathrm{e}}$ & $2.41 \pm 0.02^{\mathrm{c}}$ \\
Wereta & $23.30 \pm 0.13^{\mathrm{b}}$ & $2.32 \pm 0.07^{\mathrm{b}}$ \\
\hline
\end{tabular}

*Values are the means of triplicate determinations \pm standard deviation; values within the same column followed by different superscripts are significantly different at $P \leq 0.05$.

reported in [24]. And also, according to [21], the content of hop polyphenols ranged from 2 to $5 \%$ with a mean value of $3.5 \%$. In this case, the content of polyphenols of leaves of $R$. prinoides $(2.11 \pm 0.0-2.41 \pm 0.02 \%)$ was found to be within the range of commercial hops. The result obtained in this study suggests that $R$. prinoides leaves are a good source of polyphenols, and it may serve as an antioxidant for commercial alcoholic beverages brewing.

The result obtained from this study showed that $R$. prinoides leaves are a good source of total resin, soft resin, hard resin, $\alpha$-acid, $\beta$-acid, flavonoids, and polyphenol and were found to be comparable with that of commercial hops $[21,24]$. Thus, the amount and level of total resin, soft resin, hard resin, $\alpha$-acid, $\beta$-acid, iso- $\alpha$-acid, essential oils, flavonoids, and polyphenols of $R$. prinoides leaves collected from different sample locations were different. Such a difference and irregularities cannot be certainly explained; nevertheless, it might be attributed to a difference in geographical areas of plant sample collection, climate and weather conditions, soil types, and also a variety difference of the plant.

\section{Conclusion}

In this investigation, different physicochemical characteristics of $R$. prinoides leaves that were collected from different farmlands of the Amhara region, Ethiopia, were assessed and characterized. The results obtained from this study showed that the leaves of $R$. prinoides are good sources of bittering agents, essential oils, and antioxidants and were found in good agreement with most of the reported values of commercial hop found in the literature. However, the amount and level of bittering agents, essential oils, and antioxidants of $R$. prinoides leaves were varied with sample source sites. The factors that contributed to such variation are likely to be a difference in the plant geographical location, climatic and weather conditions, soil types, and variety difference. Thus, the result obtained in the present study can be used as a baseline to formulate bittering substance required for beer production and other alcoholic beverages. 


\section{Recommendation}

Based on the results of this study, the following recommendations have been provided:

(i) Gesho leaves are a good source of bittering agents, essential oils, and antioxidants and can be a substitute for commercial hops.

(ii) Promotion should be done to introduce the potential of Gesho as bittering agents, source of aroma, and flavor for beer and other alcoholic beverages.

(iii) Promoting further detailed investigations needed on the impact of soil type and growing environment on the quantity of bittering components, essential oils, and antioxidants of $R$. prinoides leaves.

\section{List of Abbreviations}

$\begin{array}{ll}\text { AOAC: } & \text { Association of Official Analytical Chemists } \\ \text { iso: } & \text { Isomerize } \\ \text { l: } & \text { Liter } \\ \mathrm{mg}: & \text { Milligram } \\ \mathrm{ml}: & \text { Milliliter } \\ \mathrm{rpm}: & \text { Revolution per minute. }\end{array}$

\section{Data Availability}

Upon request, the data used to support the result of this study are available from the corresponding author.

\section{Conflicts of Interest}

The authors declare that they have no conflicts of interest.

\section{Authors' Contributions}

Mr. Abebe Worku conducted all the experiments and wrote the manuscript. Mr. Belay Tilahun and Berhanu Andualem (Prof.) coordinated the research work, designed portions of the experiments, and were involved in the revision of the manuscript.

\section{Acknowledgments}

This study was supported by the Ethiopian Biotechnology Institute (EBTI), Honey Wine Project at the University of Gondar, Ethiopia. I am very grateful to express my heartfelt acknowledgment of the University of Gondar, Environmental and Industrial Biotechnology, and Department of Chemistry for providing the laboratory facilities and chemicals during laboratory work. I am also thankful to Adigrat University for giving me a scholarship and sponsoring my study.

\section{References}

[1] M. D. Dlamini and S. Turner, Rhamnus Prinoides L' Herit, Witwatersrand National Botanical Garden, South African National Biodiversity Institute, Pretoria, South Africa, 2002.

[2] M. M. Nindi, B. V. Kgarebe, J.-L. Wolfender, and B. M. Abegaz, "Electrospray liquid chromatography-mass spectrometry of the leaf extract of Rhamnus prinoides," Phytochemical Analysis, vol. 10, no. 2, pp. 69-75, 1999.

[3] B. Abegaz and T. Kebede, "Geshoidin: a bitter principle of Rhamnus prinoides and other constituents of the leaves," Bulletin of the Chemical Society of Ethiopia, vol. 9, no. 2, pp. 107-114, 1995.

[4] J. W. Kiringe, "A survey of traditional health remedies used by the Maasai of southern Kaijiado District, Kenya," Ethnobotany Research and Applications, vol. 4, pp. 061-73, 2006.

[5] G. N. Njoroge and R. W. Bussmann, "Traditional management of ear, nose, and throat (ENT) diseases in Central Kenya," Journal of Ethnobiology and Ethnomedicine, vol. 2, pp. 1-9, 2006.

[6] T. Teklehaymanot and M. Giday, "Ethnobotanical study of medicinal plants used by people in Zegie Peninsula, Northwestern Ethiopia," Journal of Ethnobiology and Ethnomedicine, vol. 3, no. 12, pp. 1-11, 2007.

[7] F. Fullas, Spice Plants in Ethiopia: Their Culinary and Medicinal Applications, Reference Publications, Inc., Sioux City, IO, USA, 2003.

[8] A. Berhanu, "Microbial profile of Tella and the role of Gesho (Rhamnus prinoides) as bittering and antimicrobial agents in traditional Tella (Beer) production," International Food Research Journal, vol. 21, no. 1, pp. 357-365, 2014.

[9] G. Afewerk and S. C. Bhagwan, "Levels of essential and nonessential metals in Rhamnus prinoides (Gesho) cultivated in Ethiopia," Bulletin of the Chemical Society of Ethiopia, vol. 26, no. 3, pp. 329-342, 2012.

[10] S. Sahle and B. A. Gashe, "The microbiology of Tella fermentation," SINET: Ethiopian journal of Science, vol. 14, pp. 81-92, 1991.

[11] B. M. Abegaz, B. T. Ngadjui, M. Bezabih, and L. K. Mdee, "Novel natural products from marketed plants of eastern and Southern Africa," Pure and Applied Chemistry, vol. 71, no. 6, pp. 919-926, 1999.

[12] R. Hayeshi, S. Mukanganyama, B. Hazra, B. Abegaz, and J. Hasler, "The interaction of selected natural products with human recombinant glutathione transferases," Phytotherapy Research, vol. 18, no. 11, pp. 877-883, 2004.

[13] A. Hailemichael, A. M. Berhanu, and B. Merhatibeb, "Electrochemical behavior and voltammetric determination of Geshoidin and its spectrophotometric and antioxidant properties in aqueous buffer solutions," Bulletin of the Chemical Society of Ethiopia, vol. 21, no. 2, pp. 189-204, 2007.

[14] W. J. Simpson and A. R. W. Smith, "Factors affecting antibacterial activity of hop compounds and their derivatives," Journal of Applied Bacteriology, vol. 72, no. 4, pp. 327-334, 1992.

[15] A. Mogessie, "A review on the microbiology of indigenous fermented foods and beverages of Ethiopia," Ethiopian Journal of Biological Sciences, vol. 5, no. 2, pp. 189-240, 2006.

[16] K. K. Adama, A. A. Oberafo, and S. I. Dika, "Bitterleaf as a local substitute for hops in the Nigerian brewing industry," Scholars Research Library, vol. 3, no. 4, pp. 388-397, 2011.

[17] C. C. Okoro and J. O. Aina, "Effect of storage on the brewing properties of tropical hop substitutes," African Journal of Biotechnology, vol. 6, no. 12, pp. 1479-1483, 2007.

[18] AOAC, Official Methods of Analysis (Chapter 27), AOAC, vol. 2p. 16, 17th edition, Rockville, MD, USA, 2000.

[19] H. O. Edeoga, D. E. Okwu, D. E. Okwu, and B. O. Mbaebie, "Phytochemical constituents of some Nigerian medicinal plants," African Journal of Biotechnology, vol. 4, no. 7, pp. 685-688, 2005. 
[20] O. Damilola, O. B. Joseph, A. Olufemi, and I. Amoo, "Chemical composition of red and white cocoyam (colocosiaesculenta) leaves," International Journal of Scientific Research, vol. 2, no. 11, pp. 121-126, 2013.

[21] W. Kunze, Technology Brewing and Malting, VLB Berlin, Berlin, Germany, 3rd edition, 2004.

[22] M. Krottenthaler, "Hops," in Handbook of Brewing: Processes, Technology, Markets, H. M. Eblinger, Ed., Wiley-VCH Verlag GmbH \& Co. KGaA, Weinheim, Germany, 2009.

[23] T. R. Roberts and R. J. Wilson, "Hops," Handbook of Brewing, vol. 2, pp. 181-266, Taylor \& Francis Group, LLC, Oxfordshire, UK, 2006.

[24] S. Hieronymus, For the Love of Hops: The Practical Guide to Aroma, Bitterness, and the Culture of Hops, pp. 1-272, Brewers Publications, Boulder, CO, USA, 2012.

[25] A. Getaw and A. Berhanu, "Production of beer using Gesho (Rhamnus prinoides) as a potential bittering agent in comparison with hop (Humulus lupulus),", M.Sc. thesis, Department of Biotechnology, University of Gondar , pp. 1-40, Department of Biotechnology, University of Gondar, 2017.

[26] M. Kovacevic and M. Kac, "Determination and verification of hop varieties by analysis of essential oils," Food Chemistry, vol. 77, no. 4, pp. 489-494, 2002. 